\title{
Desenvolvimento de referencial teórico para um sistema de informações gerenciais (SIG) para parlamentares e assessores na C âmara Legislativa do D istrito Federal: em busca de um modelo conceitual*
}

\section{M arisa P. C. Rocha}

M estre em ciência da informação. Assessora técnico-legislativa da Câmara Legislativa do Distrito Federal.

E-mail:mperrone@solar.com.br

biblioteca@cldf.gov.br

\begin{abstract}
Resumo
Procurou-se desenvolver um referencial teórico para o desenvolvimento de um modelo conceitual de sistema de informações estratégico-administrativo de apoio à decisão, com base na análise sociotécnica estruturada. Para tanto, buscou-se analisar os fatores ambientais que influenciam o processo decisório de parlamentares e assessores na Câmara Legislativa do Distrito Federal. Como resultado, foram obtidas as relações entre organização, ambiente $e$ dados, representadas graficamente, em um modelo conceitual de um sistema de informações gerenciais (SIG), para acompanhamento sistemático das informações que influenciam o contexto de atuação dos atores responsáveis pelo processo legislativo local.
\end{abstract}

\section{Palavras-chave}

Gestão da informação; Sistema de informações gerenciais; Informação legislativa; Processo legislativo; Câmara Legislativa do Distrito Federal.

Development of a theoretical referential for a system of managerial information for members and advisors of the Legislastive Chamber of the Federal District: in search of a conceptual model

\begin{abstract}
We seek to develop a referential theoretical for a conceptual model by a support information system to the decision, social-technique-structured-analysis-based. So that, we have analyzed the internal and external factors to act on representatives' and assessors' performances in the legislative process. As result, we got the relations between organization, environment and data, represented graphically, in a conceptual model.
\end{abstract}

\section{Keywords}

Information management; Management information system; Legislative information; Legislative process; Câmara Legislativa do Distrito Federal.

\section{IN TRO DUÇÃO}

No mundo moderno, diante das transformações sociais, políticas e econômicas ocorridas a partir do advento da telemática e do processo de globalização, as organizações procuram adaptar-se aos novos tempos. N esse contexto de mudança, emerge uma organização moderna, apoiada nas tecnologias da informação, atuando em rede e fundamentada na informação. Essas mudanças visam a melhorar a eficiência das empresas, que, por sua vez, buscam resultados mais satisfatórios e maior poder de competitividade em um mercado globalizante. Para alcançar a qualidade e a eficiência desejadas, as organizações devem calcar o processo decisório em um sistema de informações confiável e capaz de dimensionar o futuro, procurando compreender as mudanças e estabelecer novos rumos necessários à redução de incertezas quanto ao futuro (Barbalho \& Beraquet, 1995).

As instituições públicas brasileiras, mesmo que tardiamente, também estão procurando se inserir nesse contexto de mudanças, portanto devem envidar esforços para adequar e racionalizar seus processos de trabalho, buscando organizar seus recursos informacionais e valorizando seu capital intelectual. Gerenciar esses recursos implica planejar, estabelecer estratégias, diretrizes, metas e modelos referentes à informação, além de desenvolver princípios e técnicas que permitam a sua eficiente organização. Envolve o gerenciamento do conteúdo informacional, da tecnologia utilizada e dos recursos humanos envolvidos em todo o ciclo da informação (coleta, organização, processamento, recuperação e uso) (Cianconi, 1998).

\footnotetext{
* Apresentada originalmente como dissertação de mestrado. A primeira versão desse artigo foi aceita no KM Brasil 2002 3o W orkshop Brasileiro de Inteligência Competitiva e G estão do Conhecimento, em São Paulo, 2002.
} 
$N$ este estudo, busca-se conhecer o comportamento informacional de assessores legislativos e parlamentares na Câmara Legislativa do Distrito Federal (CLDF) como subsídio à gestão estratégica de informações no processo legislativo, verificando que elementos devem ser considerados para construção de modelo conceitual de um sistema de informações gerenciais (SIG) baseado na análise sociotécnica estruturada, para a elaboração de um sistema de informações de apoio à decisão. Com esse objetivo, procuramos investigar a estrutura do processo legislativo local e a estrutura organizacional da Assessoria Legislativa (A ssel), seu contexto de atuação e suas perspectivas; que fatores internos e externos contribuem para o desenvolvimento organizacional da Assel; quais as principais atividades de parlamentares e assessores referentes ao processo legislativo na CLDF; quais as características das informações que apóiam o desenvolvimento das atividades de parlamentares e assessores legislativos quanto à demanda, finalidade, fontes/ canais mais utilizados, recursos tecnológicos e quais os elementos de valorização da informação na organização; que elementos devem ser considerados para descrever as relações entre dados, organização e ambiente, como esses dados interagem e como essas relações podem ser representadas, oferecendo uma visão integrada e sistêmica do processo.

\section{BREVE HISTÓRICO DO PODER LEGISLATIVO NO DISTRITO FEDERAL}

A idéia de transferir a capital federal para 0 interior do país surgiu no século XIX. Em 1892, foi criada a C omissão Cruls (Comissão Exploradora do Planalto Central), com o objetivo de propor a área em que seria fixada a nova capital. Em 1922, o então presidente Epitácio Pessoa lançou a pedra fundamental da futura capital nas mediações de Planaltina de Goiás. Em 1956, Juscelino Kubitschek dá início à construção de Braślia. Em 1961, foi aprovada a Emenda C onstitucional n.3, modificando a Constituição de 1946 e concedendo representação a Brasília nas duas C asas congressuais, além de permitir criar uma câmara municipal para controlar a ação do governo local. A data das eleições, no entanto, não foi estipulada. De 1960 a 1969, a cidade foi governada por prefeitos indicados pelo presidente da República.

Com o advento do governo militar em 1964, a Emenda Constitucional n. 1 de 1969 cria o cargo de governador e institui a Comissão do Distrito Federal no Senado, que, funcionando como um legislativo, homologava as decisões do Executivo local (como o orçamento do DF), apreciava algum projeto de lei e as indicações dos conselheiros do Tribunal de Contas do Distrito Federal (Distrito Federal, 2000).
A cidade cresceu e passou a conviver com todos os problemas inerentes às grandes cidades. Além disso, as repetidas nomeações de prefeitos e governadores, que vinham sempre de outras cidades, desvinculados e fora de sintonia com os problemas locais, bem como a falta de um fórum para discussão dos problemas e reivindicações da comunidade, motivaram as entidades civis, representações políticas, associações e organizações a se articularem, reivindicando a representação política e, conseqüentemente, a autonomia política do Distrito Federal, com eleições em todos os níveis.

Em 1986, por dispositivo da Emenda Constitucional n. 25, Brasília teve assegurado o direito de eleger sua representação política em nível nacional, composta de deputados federais (8) e senadores (3). Finalmente, em 1988, a Constituição Federal permite que Brasília conquiste sua autonomia política, com eleições diretas para governador e deputados distritais, previstas para 1989. Em 1990, 30 anos após sua inauguração, assume 0 primeiro governador eleito do DF, além dos 24 deputados distritais eleitos, compondo, estes últimos, o Poder Legislativo do Distrito Federal.

Por suas características intrínsecas dos três Poderes do Estado, o Legislativo é o que mais se aproxima da sociedade, por representá-la em seus diversos segmentos. 0 Poder Legislativo representa, teoricamente, a "voz do povo", pois é por seu intermédio que os cidadãos podem acompanhar as decisões que causam maior impacto à população. Q uanto mais consciente for a escolha dos seus representantes, seja governador, seja deputado, assim como quanto maior for a participação popular junto aos parlamentares e governantes, maior legitimidade terá tanto o Poder Legislativo, quanto o Poder Executivo.

A atividade política dos deputados distritais, desde 1991, quando foi instalada a Câmara Legislativa do DF, tem se apresentado sob tensão, tanto pela questão vocacional de Brasília como cidade político-administrativa, quanto pela questão econômica - baseada na existência de um mercado emergente e complexo. Além disso, a atuação política dos deputados sofre pressão em função da questão do papel de Brasília como importante centro de influência regional do Entorno, ou, ainda, quanto à divisão dos papéis a serem exercidos pelo Executivo e Legislativo como poderes legitimamente constituídos. A Câmara Legislativa prioriza as políticas que atendam às demandas da sociedade nas áreas da educação, saúde, geração de emprego, segurança pública, meio ambiente, moradia, transportes, assistência social, entre outras. Dentro desse contexto, a partir de suas funções como Poder Legislativo legitimamente constituído, tendo por 


\section{Desenvolvimento de referencial teórico para um sistema de informações gerenciais (SIG )...}

princípios fundamentais a autonomia e a independência, definem-se seus objetivos e diretrizes (Distrito Federal, 1999).

\section{A ATIVIDADE PARLAMENTAR}

A atividade parlamentar mais envolvente é sua atuação no plenário, local onde se discutem e votam as proposições legislativas, que se transformarão em leis, decretos legislativos, resoluções, emendas à Lei O rgânica do DF etc. No plenário, travam-se os debates. A atividade parlamentar e os debates estendem-se às comissões permanentes ou temporárias. Essa atividade envolve debate com diversos segmentos da sociedade interessados nos temas apreciados pelas comissões. A ação partidária, outra atividade parlamentar, exige dos deputados permanente contato com seus correligionários, discutindo questões de natureza político-partidária e definindo estratégias de ação. U m aspecto muito importante no trabalho dos deputados é a atividade no gabinete, ocasião em que recebem seus eleitores, ouvem críticas, sugestões e reivin dicações. M uitas vezes, exercem o papel de intermediador entre o el eitorado e 0 Executivo, encaminhando pleitos, acompanhando projetos de interesse de determinadas regiões ou grupos específicos (Distrito Federal, 2000). A lém do contato no gabinete, 0 deputado procura manter intercâmbio constante com a população, em visita às diferentes regiões administrativas (conhecendo melhor os problemas da comunidade), ouvindo sugestões e colhendo subsídios para sua atuação parlamentar e legislativa. Além disso, a troca de informações possibilita à população ficar mais próxima da atividade parlamentar e influenciar no processo legislativo (Distrito Federal, 2000).

\section{METO D O LO G IA}

Estudo de caso analítico-descritivo, caracterizado como uma pesquisa de levantamento e diagnóstico. Tomamos como foco de análise organizacional a Assessoria Legislativa, formada por cinco unidades temáticas e vinculada à Mesa Diretora, e as necessidades informacionais dos deputados distritais. Para tanto, como universo de pesquisa, definimos dois grupos para análise: o primeiro, os assessores legislativos lotados nas diversas unidades temáticas e os assessores parlamentares lotados nos gabinetes. Foram indicados cinco assessores legislativos, representando cada uma das unidades temáticas da Assessoria Legislativa para participar do seminário de levantamento de dados, assim como um assessor de cada um dos 24 gabinetes.
Para a coleta dos dados, utilizamos os seguintes métodos e técnicas: a) pesquisa documentária, em todas as fases da pesquisa; b) aplicação da abordagem sociotécnica estruturada para análise organizacional, considerando os ambientes geral, organizacional e de tarefa; c) estudo de usuários, com entrevistas estruturadas e observação in loco; d) brainstorming estruturado, utilizando-se da ferramenta JAD (Joint A pplication D esign) adaptada; e) estudo de prospecção, com cenários tentativos, a partir da elaboração de um referencial teórico. 0 levantamento dos fatores ambientais e a elaboração do formulário para a aplicação das entrevistas basearam-se nos estudos De Baldwin (1999), Klaes (1991), Tarapanoff (1984) e Ponjuan Dante (1998).

\section{RESU LTADOS - 0 REFERENCIAL TEÓRICO E O SIG}

0 processo decisório no planejamento estratégico e no acompanhamento administrativo dos sistemas de informações deve estar baseado em um sistema de informações estratégico/administrativo (Tarapanoff, 1995). A abordagem sociotécnica estruturada que desenvolve a partir da análise teórico-sistêmica oferece os elementos necessários à elaboração de um referencial teórico para o gerenciamento estratégico das informações referentes ao processo legislativo, no âmbito da A ssessoria Legislativa, que subsidie a tomada de decisão de parlamentares e assessores legislativos. 0 referencial teórico é a base do modelo conceitual. Fundamentandose na literatura especializada e a partir do exame dos dados levantados, de forma a possibilitar a compreensão das necessidades e uso das informações relevantes à tomada de decisão no processo legislativo local, de parlamentares e assessores legislativos, procuramos desenvolver as relações en tre os dados levantados e como eles interagem. A figura 1, a seguir, apresenta essas relações.

Segundo o esquema apresentado na figura 1, podemos observar que a relação entre organização e ambiente oferece uma visão sistêmica, em que a Assel funciona como um sistema aberto, interagindo com seus subsistemas. A atividade de consultoria e assessoramento legislativo concentra todas as atividades desenvolvidas pela Assel, mediante serviços e produtos. A missão da Assel determina as ações a serem desenvolvidas e as decisões a serem executadas. 0 rienta ainda a formulação da visão, das políticas, dos objetivos e das atribuições da A ssel, que devem estar alinhados à missão, visão, objetivos e diretrizes da CLDF, situando no processo legislativo sua atividade-fim. A lém disso, sofre influência de seu ambiente interno (organizacional) e externo (DF 
FIGU RA 1

Contexto da atividade de consultoria e assessoramento legislativo da Assel

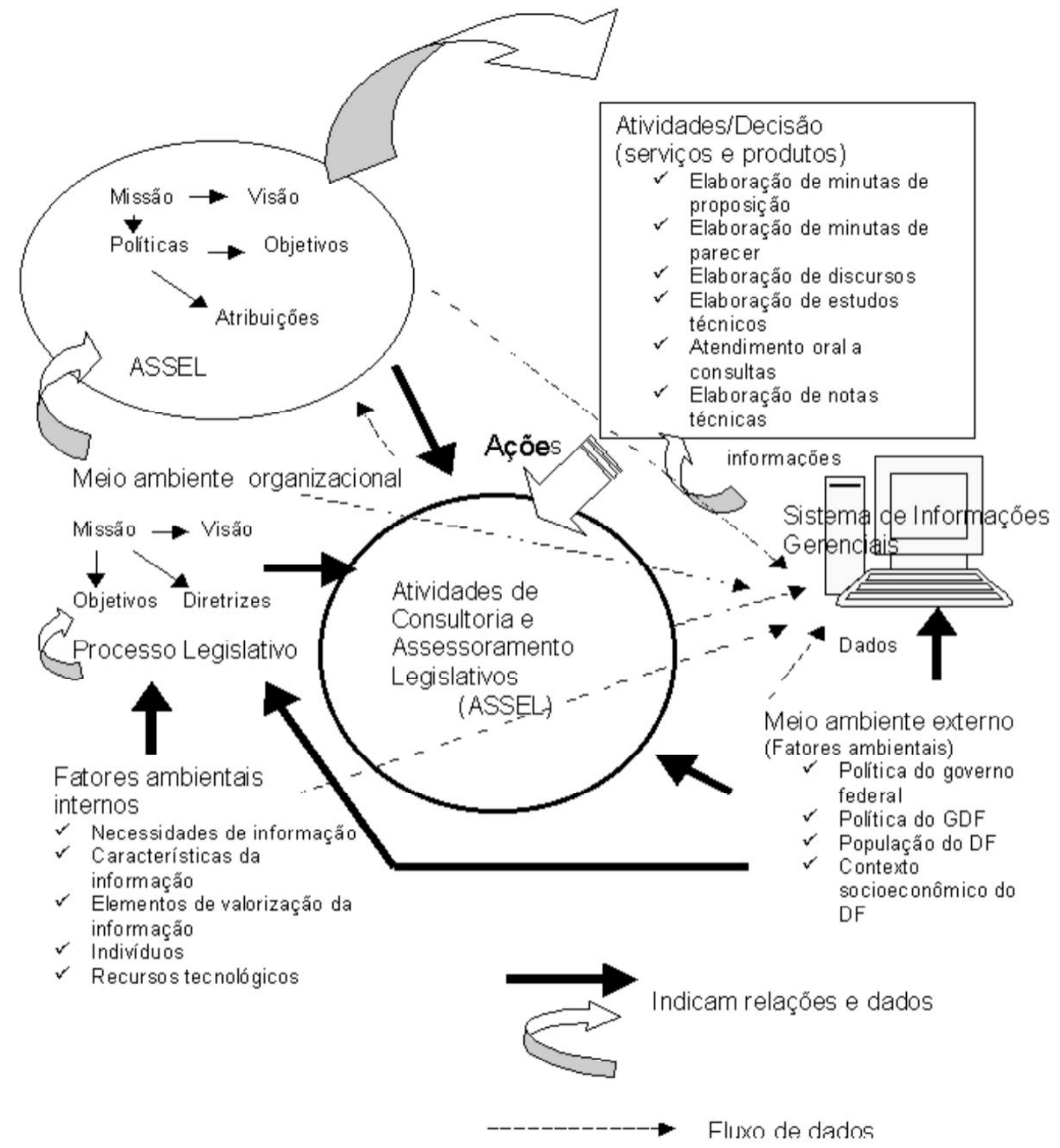

Fonte: baseado no esquema de Klaes, 1991.

e Brasil), cujos fatores fornecem dados a serem coletados e reunidos em um sistema de informação gerencial, que irá fazer, periodicamente, o monitoramento desses fatores, fornecendo insumos informacionais para a tomada de decisão e para a elaboração das estratégias organizacionais. Essas estratégias orientam as decisões; as decisões são implementadas por ações. A contextualização desses elementos, durante as discussões nas sessões de Joint A pplication Design (JAD) e durante as entrevistas, permitiu identificar os fatores ambientais que interferem na atuação da Assel na atividade parlamentar. 


\section{Desenvolvimento de referencial teórico para um sistema de informações gerenciais (SIG )...}

Para análise do ambiente interno, foram verificados documentos técnico-administrativos (planos setoriais de ação e metas, relatórios e outros) e documentos produzidos pela alta administração, os quais forneceram os dados necessários à identificação das ações previstas e executadas, estrutura, funções e políticas desenvolvidas pela organização, bem como sua missão. A análise do ambiente interno permitiu identificar os pontos fortes e fracos da organização. $\mathrm{N}$ a análise do ambiente geral (Brasil) e específico ou de tarefa (D istrito Federal), buscouse identificar, nos planos e políticas governamentais federais e locais, nos indicadores socioeconômicos, nas informações produzidas pela mídia e nos estudos encomendados sobre a organização, os eventos políticos, sociais, culturais e econômicos que possam representar ameaças ou oportunidades à organização.

A coleta de informações oriundas da mídia, ao captar esses eventos, quando busca a opinião de especialistas para esclarecer e orientar a opinião pública, abre espaço significativo à ref lexão dos fatos, condição essencial para que a sociedade seja capaz de julgar e decidir sobre a "coisa pública", sobre a direção e intenção da ação governamental. A opinião pública, em uma sociedade democrática, não atua diretamente nas decisões políticas, pois não tem poder de iniciativa, exceto nos casos previstos por lei, mas tem o poder de referendar ou não, de tornar possível ou não, uma política governamental. $N$ esse sentido, a informação veiculada pela mídia apresenta-se como importante fonte de análise do ambiente externo à organização.

A ssim, a análise dos ambientes interno e externo permitiu indicar os aspectos considerados para a elaboração do referencial teórico e para o estudo de prospecção (cenários). A pós a análise ambiental e identificação dos fatores que interferem na organização, a partir das variáveis ambientais e seus componentes estratégicos, foi possível elaborar o diagnóstico estratégico. 0 diagnóstico, uma das ferramentas para o acompanhamento administrativo, baseia-se em indicadores previamente definidos, que podem ser traduzidos em políticas e objetivos. Com base nesse diagnóstico, procuramos identificar as estratégias mais adequadas ao contexto a serem adotadas pela Assel.

Essas estratégias, no entanto, são mutáveis, como é mutável o contexto ambiental, o qual, por isso mesmo, deve ser monitorado permanentemente. 0 acompanhamento sistemático dos fatores ambientais permitirá controlar e adequar as estratégias organizacionais às mudanças do meio, de forma que as mudanças ocorridas não afetem a eficácia organizacional. 0 modelo conceitual, quando implementado, permitirá aos desenvolvedores de sistemas da CLDF projetar um sistema de monitoramento de informações, o qual, por sua vez, permitirá acompanhar sistematicamente os dados identificados para coleta, tratamento e armazenamento, reunidos e organizados em um sistema de informações gerenciais - ou estratégico-administrativo -, de forma a serem utilizados sempre que necessário. Esses dados com valor agregado passam a subsidiar a tomada de decisão referente ao processo legislativo. As figuras 2 e 3 , a seguir, respectivamente, apresentam um esquema simplificado do processo de tomada de decisão no processo legislativo e na A ssel, com base no esquema apresentado por Klaes (1991, p. 95) e a partir dos dados identificados em M ezey (apud C unha, 1987).

A função legislativa, como observa M ezey (citado por Cunha, 1987), constitui processo decisório envolvendo iniciativa, formulação, decisão e implementação. U ma vez identificada a demanda de informação, esta deve estar de acordo com a missão da CLDF, seus objetivos e diretrizes, a fim de formular adequadamente as questões propostas e iniciar o processo. Este se inicia mediante 0 levantamento de dados e informações, identificando os fatores ambientais internos e externos que atuam sobre a proposição e verificando seu impacto na organização e na sociedade. Esses dados e informações irão subsidiar a geração de opções a serem apresentadas, culminando com a formulação de uma proposição formal. A iniciativa é prerrogativa do legislador, e a geração de opções é função dos assessores (legislativos e parlamentares), em forma de minutas de proposição e pareceres.

A próxima etapa diz respeito à deliberação, quando as opções encontram-se reduzidas e os estudos sobre a matéria estão praticamente esgotados. $N$ essa fase, a proposta é discutida e, se for o caso, alterada. Procedese, então, à decisão de aproveitar ou rejeitar o projeto. A participação do deputado nessa fase é de ação (deliberação). A proposição é encaminhada para sanção ou veto. A etapa seguinte, final, refere-se à implementação da lei para que se produza seu efeito (eficácia da lei). A aplicação da lei depende de seus executores. N esse momento, as decisões são avaliadas quanto à necessidade de alteração, revogação ou ampliação da lei. A participação do legislador é de fiscalização ou defesa da ação governamental. 
0 processo decisório na Assel assemelhase ao esquema referente ao processo legislativo. 0 processo se inicia com a identificação da demanda de informação, considerando-se a missão, objetivos, políticas e atribuições da Assessoria Legislativa, que, por sua vez, devem estar alinhados à missão, objetivos e diretrizes da CLDF. N esse momento, identificamse os dados a serem coletados. A seguir, procede-se à identificação dos fatores ambientais internos e externos que influenciam a atuação da Assel, verificando seu impacto social e organizacional.

A próxima etapa referese à seleção, coleta, organização e análise dos dados. N essa fase, consideram-se as decisões a serem tomadas e já se têm as alternativas a serem apresentadas aos decisores finais. Em seguida, são propostas ações em função das atividades e dos fatores ambientais e em função das políticas e objetivos definidos. 0 produto final apresenta-se sob a forma de minutas de proposição ou parecer, estudo ou nota técnica, ou resposta a consultas formuladas.

Finalizando o processo, as ações são implementadas. $N$ essa fase, procede-se ao estabelecimento de prioridades e análise das ações propostas. A partir da análise sociotécnica estruturada realizada e da identificação e exame dos fatores ambientais, procuramos estruturar um modelo conceitual que subsidie a elaboração de um sistema de informação gerencial (SIG) para a Assessoria Legislativa (A ssel). O s fatores do ambiente organizacional que influenciam a atuação da Assel dizem respeito à missão, visão, objetivos e diretrizes da CLDF, bem como à missão, visão, objetivos, atribuições, políticas e estrutura organizacional da própria Assel.

Os indivíduos representam os usuários-meio, que são os alimentadores do sistema, representados pelos assessores e assistentes legislativos, e os usuários-fim, que são os parlamentares e seus assessores diretos, os clientes do sistema. Os serviços e produtos referem-se às atividades desenvolvidas pela Assessoria Legislativa e os produtos delas decorrentes, que são organizados em bases de dados

FIGURA 2
Tomada de decisão no processo legislativo

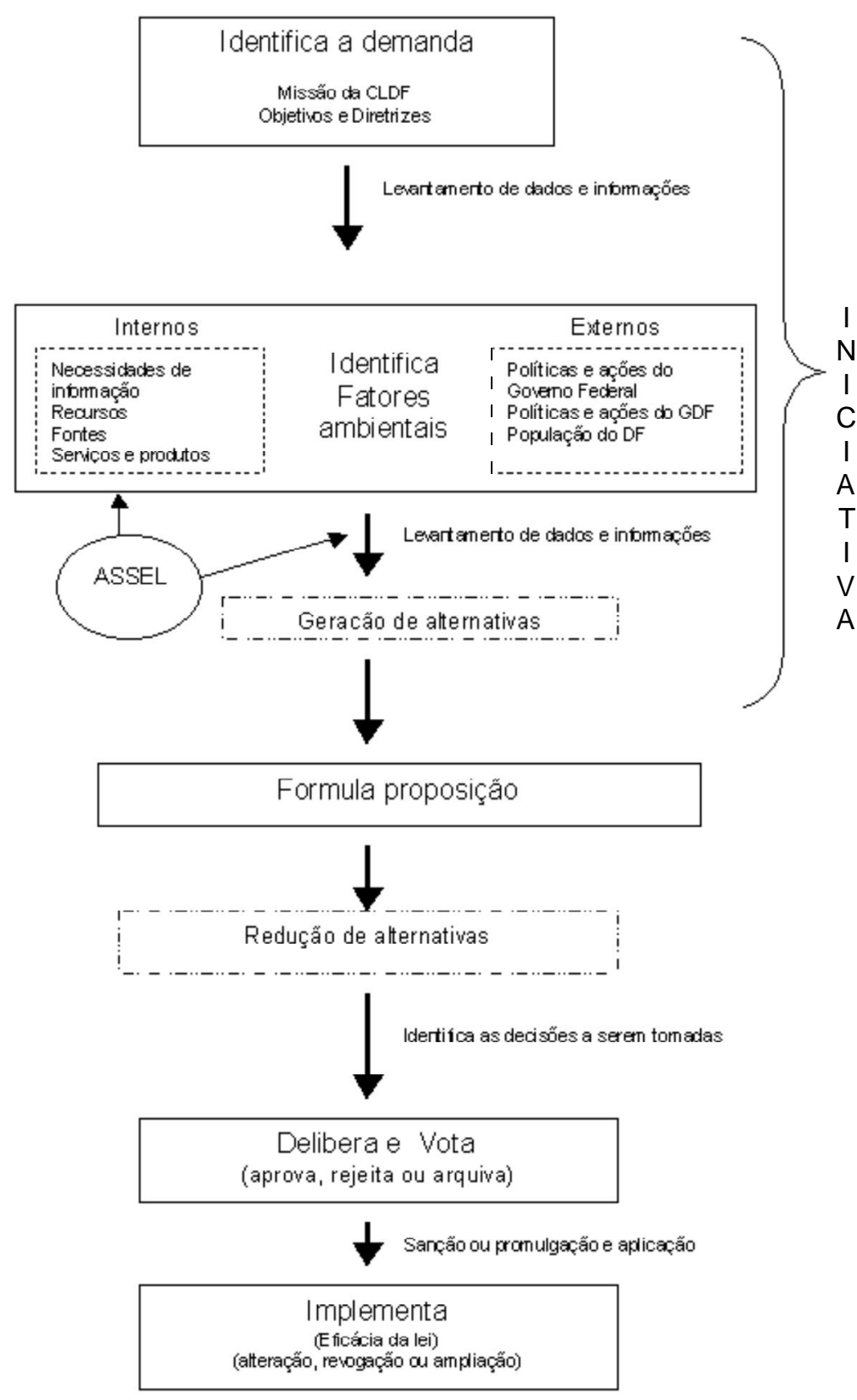

internas a cada unidade temática, ou integradas em uma base única do setor. Além desses serviços e produtos, a A ssel é usuária de vários outros distribuídos pelos setores da CLDF que a auxiliam no desenvolvimento de suas atividades, como Biblioteca e Arquivo, Protocolo Legislativo e Setor de Taquigrafia, além de outras instituições, como a Câmara dos D eputados, Senado Federal e Supremo Tribunal Federal. A necessidade de informação representa fator fundamental, pois origina a demanda de informações na Assel. 
A necessidade de informação dos parlamentares depende da área de atuação parlamentar e refere-se à origem dessa demanda para o deputado e sua finalidade, ao tipo de informação prioritária para sua atuação e às fontes de informação mais utilizadas pelo parlamentar. I gualmente importante, as características da informação dizem respeito à finalidade da informação demandada do legislador para a Assel, ao tipo de informação prioritária ao desenvolvimento das atividades da Assel, às fontes e canais mais utilizados pelos assessores legislativos e às dificuldades de acesso a essas informações.

Os elementos de valorização da informação na Assel referem-se aos indicadores da qualidade dessas informações, à utilização dos fundos informacionais, ao impacto da informação na produtividade e eficácia organizacional e ao posicionamento dos recursos financeiros para o setor. Os instrumentos de avaliação da satisfação dos usuários são, igualmente, fator preponderante, e a inexistência desse instrumento na Assel tem gerado problemas de motivação e na obtenção do feedback positivo ou negativo quanto ao atendimento das necessidades de informação de seus usuários e quanto à qualidade de seus produtos e serviços.

Os recursos tecnológicos são de importância fundamental para a implementação de um sistema de informação gerencial, pois vão garantir a inovação tecnológica e possibilitar agilizar as atividades.

Os fatores ambientais externos permitem 0 posicionamento proativo da Assel diante das contingências ambientais e referem-se às ações e políticas do $G$ overno do $D F$, à infra-estrutura dos serviços públicos do DF e condições socioeconômicas do DF, abrangendo o nível de desemprego e desenvolvimento humano, qualidade de vida, nível de criminalidade e violência urbana, crescimento da economia informal e proteção ambiental, no âmbito do DF e em termos de Brasil, às ações e políticas do governo federal, à situação socioeconômica do país e ao relacionamento do governo federal com o Congresso Nacional.

\section{FIGURA 3}

Tomada de decisão na A ssel/CLDF

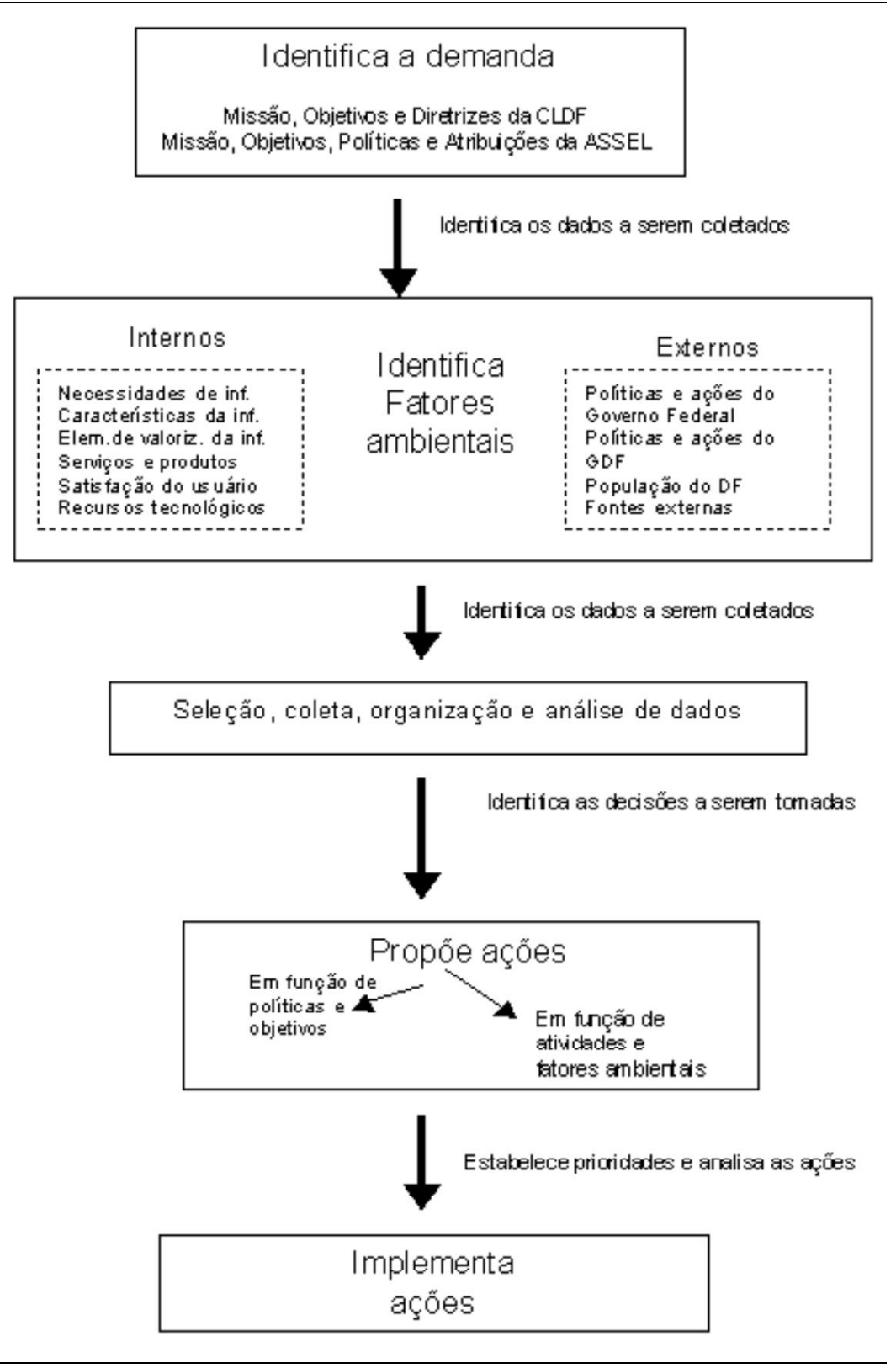

Para alcançar os objetivos traçados, verificamos que 0 monitoramento de informações constitui componente do sistema de informação gerencial (SIG). N esse sentido, o modelo conceitual idealizado a partir do levantamento do referencial teórico refere-se à modelagem de um SIG para a tomada de decisão na Assel (figura 3).

\section{CONSIDERAÇÕES FINAIS}

Tendo a Câmara Legislativa do Distrito Federal e, em especial, a Assessoria Legislativa como objeto de estudo, buscamos conhecer a necessidade e o uso das informações 
que efetivamente possam subsidiar a tomada de decisão de parlamentares e assessores legislativos no âmbito da Câmara Legislativa do Distrito Federal (CLDF), examinando os elementos que devem ser considerados para construção de um modelo conceitual voltado ao desenvolvimento de um sistema de informações de apoio à decisão referente ao processo legislativo.

Para tanto, buscamos examinar a estrutura do processo legislativo local na estrutura organizacional da Assessoria Legislativa, seu contexto de atuação e suas perspectivas; buscamos examinar os fatores internos e externos que contribuem para o desenvolvimento organizacional da Assel, as principais atividades de parlamentares e assessores legislativos, a origem e finalidade da demanda de informações, fontes e canais mais utilizados, assim como os elementos de valorização da informação na organização. Além disso, procuramos examinar as relações entre dados, organização e ambiente, como interagem e como podem ser representados, a fim de oferecer uma visão integrada e sistêmica dessas relações.

A iniciativa para a realização da pesquisa originou-se da constatação da lacuna existente na Câmara Legislativa do DF quanto à gestão da informação, e foi motivada pela necessidade de se buscar compreender o papel da informação na tomada de decisão referente ao processo legislativo, procurando conhecer a postura de parlamentares e assessores legislativos quanto ao ciclo informacional.

A revisão de literatura nos forneceu os elementos necessários para a formulação dos pressupostos e para a identificação dos fatores ambientais que poderiam exercer influência sobre a atuação da Assel, a serem levantados e examinados, além de nos orientar quanto aos métodos e procedimentos utilizados na execução da pesquisa.

A realização dessa pesquisa evidenciou a necessidade de se desenvolver um sistema de informação gerencial para a A ssessoria Legislativa. A implementação do SIG/A ssel poderia servir como um projeto-piloto de um sistema legislativo, abrangendo todas as funções da CLDF.

Partindo dessa evidência, levanta-se a questão da necessidade de adequação do modelo organizacional às novas necessidades de utilização dos insumos informacionais, já que a melhoria do desempenho organizacional depende do alinhamento da organização às estratégias definidas, do conhecimento do que impede a realização dessas estratégias e da implementação das mudanças necessárias à sua execução. Esse alinhamento depende do uso efetivo da informação transformada em conhecimento.

O s sistemas de informação existentes na Casa, dos quais a Assessoria Legislativa e os deputados distritais são usuários, aten dem parcialmente às suas necessidades de informação. Auxiliam na execução das atividades parlamentares e de assessoramento legislativo, mas operam de forma não integrada. Estão dispersos nos vários setores que apóiam o processo legislativo, ocorrendo duplicidade de dados e tarefas. Constatamos, assim, a necessidade de se desenvolver um sistema de informação que integre os subsistemas de informação documentária existentes e insira o componente estratégico, considerando missão e objetivos da Assel e da CLDF, e a necessidade de monitorar os fatores ambientais internos e externos que interferem na atuação da A ssel, de forma a gerar informação de apoio à decisão no processo legislativo mediante oferta de um sistema eficiente e eficaz.

0 sistema de informações gerenciais (SIG) desen volvido, além de permitir o monitoramento ambiental, favorece o processo de transformação de dados em informações e destas em ações, oferecendo insumos ao processo decisório e à gestão da informação, de forma que as informações produzidas pelo sistema atuem como insumos ao estabelecimento de estratégias e ações que favoreçam o desempenho organizacional.

O s serviços e produtos oferecidos pelo SIG deverão basear-se nos seguintes parâmetros:

- canalizar as informações de interesse do parlamentar;

- gerar as informações necessárias ao desenvolvimento da atividade que irá subsidiar a apresentação de proposições e permitir a percepção de como as instituições públicas têm tratado o erário público;

- gerar as informações necessárias para permitir a percepção dos problemas da comunidade e possibilitar aos parlamentares entrar em sintonia com os anseios da sociedade e dos segmentos que demandam o problema;

- gerar as informações necessárias para alimentar o feeling positivo do que é legislável, possibilitando ao parlamentar preencher os espaços dos direitos do cidadão nos direitos difusos;

- agilizar os serviços de atendimento ao cidadão, permitindo ao deputado estreitar suas relações com a sociedade; 


\section{Desenvolvimento de referencial teórico para um sistema de informações gerenciais (SIG )...}

- subsidiar o trabalho dos assessores parlamentares e legislativos que agregam valor à informação, mediante estudos técnicos, entre outros, que servem de base às políticas públicas. Para isso, os assessores devem contar com um serviço de informação seletiva (SID) de qualidade que permita obter as informações de difícil acesso;

- permitir a acessibilidade física dos fundos de informação em tempo hábil, inclusive a fundos externos;

- permitir o tratamento adequado e contextualizado da informação, mediante um serviço de análise da informação realizado por especialistas, absorvendo os indicadores de qualidade da informação e gerando informação de alto valor agregado;

- permitir a seletividade das informações produzidas;

- permitir a acessibilidade intelectual (gestão do conhecimento);

- permitir o acesso a inovações tecnológicas;

- implementar o desenvolvimento das atividades orientadas para processos, utilizando-se de tecnologias do tipo workf low para otimizar o desen volvimento dessas atividades;

- implementar o serviço de e-mail, inserido no workf low;

- reorganizar os fundos de informação.

\section{REFERÊ N C I AS}

BALDW IN, M . P. 0 fluxo da informação nas comissões permanentes da Assembléia Legislativa da Bahia. Brasília, 1999. 169 f. Dissertação (M estrado em Ciência da Informação) - D epartamento de Ciência da Informação e Documentação, U niversidade de Brasília, Brasília, 1999.

BARBALHO, C. R. S., BER AQUET, V. S .M. Planejamento estratégico para unidades de informação. São Paulo : Polis, 1995. 65 p.

CIANCONI, Regina de Barros. Gestão de documentos : uma revisão. informare. C aderno do Programa de Pós-G raduação em Ciência da Informação, Rio de Janeiro, v .4, n.1, p. 4-30, jan./ jun. 1998.

CU N H A, R. S. Serviço de informação no poder legislativo : estudo comparativo entre Estados U nidos, Grã-Bretanha e Canadá. Brasília : Câmara dos Deputados, 1988.

DISTRITO FEDERAL (Brasil). Câmara Legislativa. Grupo de Resgate da M emória da Câmara Legislativa do Distrito Federal. Memória da Câmara Legislativa do DF. 1998-2000. Brasília, v. 1-2.

Câmara Legislativa. Diretoria de Recursos Humanos. Planejamento estratégico 1999/2000. Brasília, [1999].

KLAES, R.R. Sistema de informação gerencial para desenvolvimento de coleções. Ciência da Informação, Brasília, v. 20, n. 2, p. 220-228, jul./ dez. 1991.

PONJUÁN DANTE, G. Gestión de información en las organizaciones : principios, conceptos y aplicaciones. Santiago: Universidad de Chile, 1998.

QUEM é quem na Câmara Distrital. Brasília : DIAP, 1991. 115 p.

TARA PAN OFF, K. Biblioteca integrada e sociedade : referencial teórico. Ciência da Informação, Brasília, v. 13, n. 1, p. 3-9, jan./ jun. 1984.

Técnicas para tomada de decisão nos sistemas de informação. Brasília : Thesaurus, 1995. 163 p. 